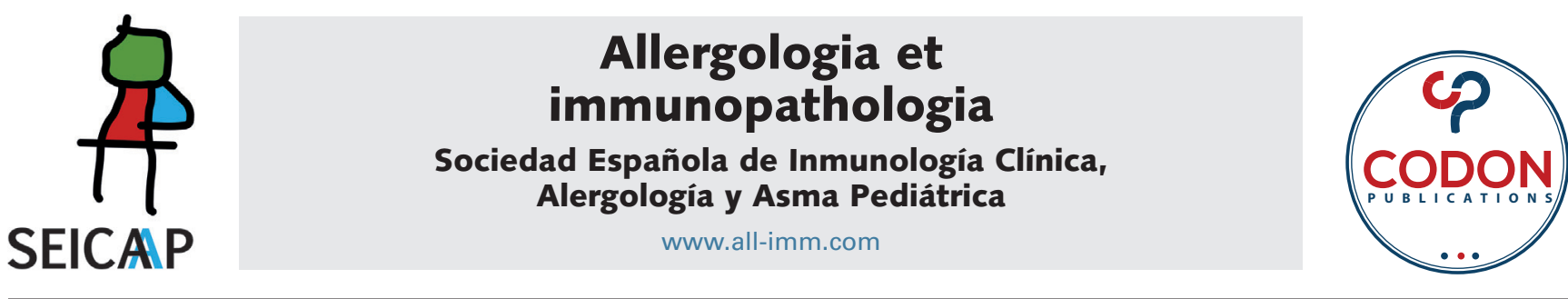

POINT OF VIEW

\title{
The traditional Mediterranean diet is effective in the prevention and treatment of acute and recurrent inflammatory diseases of childhood
}

\author{
Fernando M. Calatayud-Sáez*
}

Child and Adolescent Clinic "La Palma”, Ciudad Real, Spain

Received 20 December 2021; Accepted 21 January 2022

Available online 1 March 2022

\section{KEYWORDS \\ Inflammatory disease; recurrent disease; recurrent colds; recurrent acute otitis media; recurrent acute rhinosinusitis; otitis media with effusion; persistent nasal obstruction; childhood asthma; Mediterranean diet; dietary intervencion; nutritional therapy}

\begin{abstract}
In the recent SARS-CoV-2 pandemic, disease severity was found to be more related to the immune system hyper-response than the invasive or destructive capacity of the virus. Similarly, most common childhood diseases, which are generally recurrent and inflammatory, may be caused by a hyper-response or inability of the immune system. Individuals will react differently to causal noxa and outcomes will depend on the balance and maturity of their immune system. Conventionally, childhood diseases are symptomatically treated with little attention being devoted to balancing and stimulating the maturation of the immune system. Recently, there has been an increase in publications that consider lifestyle as an important factor in the maintenance of health. One controversial angle is an abandonment of the traditional diet and the inclusion of foods that are potentially less well-assimilated by the human species. An increasing number of studies are demonstrating the anti-inflammatory effects of the Mediterranean Diet while illustrating the pro-inflammatory effects of many other food types. We believe that the Traditional Mediterranean Diet consists of foods that support the establishment and maintenance of a healthy microbiota and a mature immune system that, in turn, can aid in the prevention of common inflammatory and recurrent diseases of childhood. (c) 2022 Codon Publications. Published by Codon Publications.
\end{abstract}

\section{Introduction}

The recent pandemic caused by SARS-CoV-2 served as a reminder that while many people (especially children and adolescents) can block this virus with an apparent naturalness, ${ }^{1}$ a hyper-response of the immune system (i.e., overproduction of antibodies [cytokine storm]) in others may result in various diseases. We could agree that the signs and/or symptoms that characterize these diseases might not only be caused by the etiological noxa but also

*Corresponding author: Fernando M. Calatayud-Sáez, Child and Adolescent Clinic "La Palma", Ciudad Real, Spain. Email address: altayud1@gmail.com 
by different defense responses. Individuals may react differently and their response, including unique signs and/or symptoms, will characterize their illness. Therefore, the classic axiom that there are "no diseases, but sick people" might be valid since people respond differently to the same causal agent. A strong and balanced defense system should block or control the disease-causing agent(s), whereas a weak or defective defense system would not be able to recognize and adequately cope with the causal noxa and would thus result in the development of symptoms that characterize the disease..$^{2-4}$

Most childhood inflammatory diseases (i.e., altered inflammatory systems) may be a result of the inability of an immune system or the hyper-response thereof. These are medical conditions that can be continually repeated, not due to the initial noxa, but due to new disease variants and/ or the poor immune response of an individual. For example, children attending school can be repeatedly affected by a cold and, together with frequent bacterial complications, can have a significant negative impact on a family. Conventional medicine will generally focus on the etiological and symptomatic treatment of the disease, repeatedly treating each acute episode but neither evaluating the poor immune response of the patient nor attempting to balance or strengthen the patient's defensive system. Antipyretics, analgesics, and anti-inflammatory drugs are generally applied (along with an antibiotic should the affectation be significant or suspected as being bacterial), and these treatments are often effective. While the latter may allow for a marked improvement within days, relapses within patients remain frequent-as does the occurrence of new catarrhal episodes and new complications. ${ }^{5}$

While their poor immune response to physical or infectious agents (not significantly affecting other children) may be overlooked or ignored, these patients will likely relapse when they encounter new agents (as their defensive systems are not working properly). Such inflammatory and recurrent diseases (IRDs), typical of childhood, can continually recur over a long period without responding to etiological or symptomatic treatments. The high consumption of drugs (that can cause increasingly defined side effects) associated with the treatment of IRDs has resulted in high morbidity during the first years of life. This, along with the increase in bacterial resistance, has led to the abandonment of many drugs and pediatricians trying to avoid any unnecessary drug treatments. ${ }^{6}$

Together with nutritionists, many teams have therefore started to work on alternative therapies. For example, a model of defensive system restorative therapy has been based on the application of the traditional Mediterranean diet (TMD) and the elimination of nontraditional antigenic products. By applying TMD guidelines (which can help restore and balance the defensive system by aiding the recognition function of the immune system without overloading it), we could act against common acute diseases in a preventative manner in healthy children-even starting from the moment of birth. When applying TMD guidelines to patients with IRD who suffer from poor defensive responses, this approach is defined as nutritional therapy. The potential misuse and manipulation by the food industry (for its own benefit) could be avoided by pointing out those foods that are not suitable as part of a standard TMD approach-the latter having been nominated as a "World Heritage and Cultural Good" by UNESCO. ${ }^{7}$ The Mediterranean Diet Foundation has since been created in parallel to enhance its knowledge and development, ${ }^{8}$ while multiple studies have been aimed at delimiting characteristics via pyramids, plates, and questionnaires.

In pediatrics, one of the most frequent IRDs is childhood asthma or recurrent wheezing which have long been linked to the abandonment of the traditional diet $t^{9,10}$ (although there is hardly any data that correlate inadequate diets with other IRDs). At present, there are numerous studies relating the Mediterranean diet to alterations of the immune system, low-grade inflammation, and the appearance of IRDs. ${ }^{11}$ Childhood colds caused by viruses are usually the triggers of childhood asthma and other IRDs (with excessive disease relapses in patients presenting with an IRD). ${ }^{12,13}$ The most common IRDs configured during childhood are recurrent acute otitis media, recurrent acute rhinosinusitis, recurrent pharyngotonsillitis, otitis media with effusion, and recurrent wheezing or childhood asthma (SW). Because of repeated catarrhal processes and persistent inflammation of the respiratory mucosa, a local lymphatic system response will be induced-leading to lymph, tonsil, and adenoid hypertrophy. This may, in turn, cause a persistent nasal obstruction (PNO) that retains mucus and prevents adequate nasal breathing. Sometimes PNOs can even make oral swallowing difficult (due to the large sizes reached by some of these structures) and may prompt surgical intervention.

A few weeks after initiating nutritional therapy for IRDs, a decrease in acute diseases (and their recurrent episodes) has been observed-inspiring loyalty to the approach. This represents a crucial factor in the success of nutritional therapy because adherence to TMD depends largely on nutritionists teaching patients to successfully discriminate between food types and their health implications. Most of the patients who have participated in these studies obtained satisfactory and statistically significant results, which is why there was a striking decrease in IRD. ${ }^{14-18}$ Furthermore, results were equally satisfactory (with a striking decrease in acute and recurrent diseases as well as on-demand consultations due to illness) ${ }^{19}$ when applying TMD therapy from birth by favoring breastfeeding and incorporating foods typical of the Mediterranean area while limiting nontraditional foodstuffs. According to these research findings, infant morbidity could dramatically decrease should children complete a quality TMD. Additionally, TMD nutritional therapy may decrease the prevalence of IRDs, decrease the consumption of drugs and the necessity for surgical interventions while increasing the efficacy in causal noxa responses. ${ }^{20}$

Some foods of animal origin (e.g., red meat, processed meats, cow's milk, and convenience foods) may be the cause, among others, in providing antigens not recognizable by the human body and thus leading to a deconfiguration of the immune and inflammatory systems. While there are no reliable tests that can accurately detect foods that trigger low-grade inflammation, it has been verified that children who eat an excess of refined flours and processed foods of animal origin (along with infrequent consumption of fruits and vegetables) have elevated inflammatory markers. These children could be in a pro-inflammatory state ${ }^{21}$ 
as there is evidence that diet and individual nutrients may influence the appearance of systemic markers of immune function and inflammation. ${ }^{22}$ The pro-inflammatory actions of platelet-activating factor, one of the most powerful endogenous mediators of inflammation, could thus be modulated by TMD to favorably regulate its metabolism. ${ }^{23}$

As highlighted by many studies, it is important to notice the potential change required for the "model of medicine." Remedying a disease with drugs and/or surgical interventions no longer represents the only viable option(s) as therapeutic approaches (providing the body with everything it needs to function properly and eliminating that which is not required) have great potential. We indicate that nutritional therapy is efficient and successful in restoring the defensive system, although the underlying mechanisms affecting the immune and inflammatory systems require more in-depth research. We believe that most IRDs are preventable and can be treated with nutritional therapy (empowering the immune and inflammatory systems against the usual processes of childhood). Clinical trials, in collaboration with nutritionists, should be carried out to further assess this hypothesis. In addition, the absence of nutritionists in the healthcare system and the neglected teaching of clinical nutrition in medical schools should become less arbitrary.

\section{References}

1. Pérez-Araluce R, Martínez-González MA, Fernández-Lázaro $\mathrm{Cl}$, Bes-Rastrollo M, Gea A, Carlos S. Mediterranean diet and the risk of COVID-19 in the "Seguimiento Universidad de Navarra" Cohort. Clin Nutr. 2021;50261-5614(21)00190-4. https://doi. org/10.1016/j.clnu.2021.04.001

2. Marcos A. Editorial: A review of micronutrients and the immune system-Working in harmony to reduce the risk of infection. Nutrients. 2021;13(11):4180. https://doi.org/10.3390/ nu13114180

3. Gombart AF, Pierre A, Maggini S. A Review of Micronutrients and the immune system-Working in harmony to reduce the risk of infection. Nutrients. 2020;12(1):236. https://doi.org/ 10.3390/nu12010236

4. Calder PC, Carr AC, Gombart AF, Eggersdorfer M. Optimal nutritional status for a well-functioning immune system is an important factor to protect against viral infections. Nutrients. 2020;12(4):1181. https://doi.org/10.3390/nu12041181

5. Childs CE, Calder PC, Miles EA. Diet and immune function. Nutrients. 2019;11(8):1933. https://doi.org/10.3390/nu11081933

6. NIDA. Overview. National Institute on Drug Abuse website. Available from: https://www.drugabuse.gov/publications/research-reports/misuse-prescription-drugs/overview. Accessed November 18, 2021.

7. UNESCO. Mediterranean diet. Representative list of the intangible cultural heritage of humanity. Cyprus, Croatia, Spain, Greece, Italy, Morocco, Portugal. 2013. Available from: http:// www.unesco.org/culture/ich/es/RL/00884

8. Bach-Faig A, Berry EM, Lairon D, Reguant J, Trichopoulou A, Dernini S, et al. Mediterranean Diet Foundation Expert Group. Mediterranean diet pyramid today. Science and cultural updates. Public Health Nutr. 2011;14(12A):2274-84. https:// doi.org/10.1017/S1368980011002515
9. García-Marcos L, Castro-Rodríguez JA, Weinmayr G, Panagiotakos DB, Priftis KN, Nagel G. Influence of Mediterranean diet on asthma in children: A systematic review and meta-analysis. Pediatr Allergy Immunol. 2013;24:330-8. https://doi.org/10.1111/pai.12071

10. García-Marcos L. Mediterranean diet as a protection against asthma: Still another brick in building a causative association. Allergol Immunopathol (Madr). 2016;44(2):97-8. https//doi. org/10.1016/j.aller.2016.02.001

11. Bach-Faig A, Berry EM, Lairon D, Reguant J, Trichopoulou A, Dernini $S$, et al. Mediterranean diet pyramid today. Science and cultural updates. Public Health Nutr. 2011;14(12A):227484. https://doi.org/10.1017/S1368980011002515

12. Castro-Rodríguez JA. What are the real effects of the Mediterranean diet on recurrent colds and their complications? Allergol Immunopathol (Madr). 2017;45(5):415-6. https://doi.org/10.1016/j.aller.2017.02.002

13. Calatayud-Sáez F, Calatayud B, Gallego JG, González-Martín C, Alguacil LF. Effects of Mediterranean diet in patients with recurring colds and frequent complications. Allergol et immunopathol (Madr). 2017;45(5):417-24. https://doi.org/10.1016/j. aller.2016.08.006

14. Calatayud-Sáez FM, Calatayud B, and Calatayud A. Recurrent acute otitis media could be related to the pro-inflammatory state that causes an incorrect diet. Progr Nutr. 2021. Pending publication.

15. Calatayud-Sáez FM, Calatayud B, Calatayud A. Effects of the traditional Mediterranean diet in childhood recurrent acute rhinosinusitis. Sinusitis. 2021;5(2):101-15. https://doi. org/10.3390/sinusitis5020011

16. Calatayud-Sáez FM, Calatayud B, and Calatayud A. Effects of the traditional Mediterranean diet in patients with otitis media with effusion. Nutrients. 2021;13:2181. https://doi. org/10.3390/nu13072181

17. Calatayud-Sáez FM, Calatayud B, and Calatayud A. Persistent nasal obstruction: An expression of the pro-inflammatory state? Sinusitis. 2021;5:90-100. https://doi.org/10.3390/ sinusitis5010010

18. Calatayud-Sáez FM, Calatayud B, Gallego JG, GonzálezMartín C, Alguacil-Merino LF. Mediterranean diet and childhood asthma. Allergol Immunopathol (Madr). 2016;44(2):99-105. https://doi.org/10.1016/j.aller.2015.04.007

19. Calatayud-Sáez FM, Calatayud B, Luque M, Calatayud A, Gallego JG, Rivas F. Effects of affinity to the Mediterranean Diet pattern along with breastfeeding on childhood asthma, inflammatory and recurrent diseases in an intervention study. Allergol Immunopathol (Madr). 2021;49(6):48-55. https://doi. org/10.15586/aei.v49i6.338

20. Calatayud-Sáez FM, Calatayud B, Calatayud A. Effects of the Mediterranean diet on morbidity from inflammatory and recurrent diseases with special reference to childhood asthma. Nutrients 2022, 14, 936. https://doi.org/10.3390/nu14050936

21. González-Gil EM, Tognon G, Lissner L, Intemann T, Pala V, Galli $C$, et al. Prospective associations between dietary patterns and high sensitivity C-reactive protein in European children: The IDEFICS study. Eur J Nutr. 2018;57(4):1397-407. https://doi.org/10.1007/s00394-017-1419-x

22. Venter C, Eyerich S, Sarin T, Klatt KC. Nutrition and the immune system: A complicated tango. Nutrients. 2020;12(3): 818. https://doi.org/10.3390/nu12030818

23. Nomikos T, Fragopoulou E, Antonopoulou S, Panagiotakos DB. Mediterranean diet and platelet-activating factor; systematic review. Clin Biochem. 2018;60:1-10. https://doi.org/10.1016/j. clinbiochem.2018.08.004 